with mesenteric panniculitis without skin and SCF involvement; the remaining 2 were not biopsied in hard to access areas. Histopathological study ruled out the probability of neoplasms and confirmed the diagnosis of lobular panniculitis in all specimens.

Therapy included such common in rheumatology practice agents as glucocorticosteroids, NSAIDs, cytotoxic drugs, hydroxychloroquine, and oths). Therapeutic success was documented in $62,68 \%$ cases, therapeutic failure and disease progression - in 17,91\% (12 patients), requiring dose escalation and modification of therapeutic regimen.

Conclusions: Identified correlation between clinical features and lab parameters measuring disease activity confirms ILP as a systemic inflammatory disease of the connective tissue. There's a flagrant necessity to improve physicians awareness of ILP, as well as need in future studies to enable earlier ILP diagnosis and identify more effective treatment of the disease.

Disclosure of Interest: None declared

DOI: 10.1136/annrheumdis-2018-eular.2091

\section{AB1154 INCREASE GENERATION BUT DEFECTS OF SECRETING IFN-A PLAY A ROLE IN THE PATHOGENESIS OF IGG4-RD}

\section{P. Zhang, W. Zhang. Peking Union Medical College Hospital, Beijing, China}

Background: IgG4 related disease (IgG4-RD) is a multi-organ involvement, fibro-inflammatory disease of unknown etiology. Both innate and adaptive immunity played vital roles in the pathogenesis of IgG4-RD. Plasmacytoid dendritic cells (pDC) had major roles in antigen presentation and secreting IFN-a upon infection. However, the characteristics and relevant function of this cell population in IgG4$\mathrm{RD}$ was poorly understood. So we aim to study the expression and function of $\mathrm{pDC}$ in IgG4-RD.

Objectives: To study the expression and function of Plasmacytoid dendritic cells (pDCs) in IgG4-RD

Methods: Flow cytometry was performed to analyse the expression of $\mathrm{pDC}$ cells in untreated IgG4-RD patients $(n=12)$ and healthy controls $(n=12)$. The immunehistochemeistry technique was used to assess the location of $\mathrm{pDC}$ in the involved tissues of IgG4-RD patients. Furthermore, by cells culture in vitro, the abilities of pDC secreting INF- $\alpha$ and the activation of NF-kB signal in IgG4-RD were explored.

Results: The frequencies of $\mathrm{pDC}$ in the IgG4-RD patients were significantly higher in the peripheral blood and involved tissues compared with healthy controls. The cell surface marker of CCR7 in pDC was lower in untreated lgG4-RD patients, but after treatment, the expression of CCR7 increased. There was on significance of the expression of pDC maturation marker (CD83), activation marker (CD80, CD86), CCR1, CCR2, CCR3, CCR4, CCR5, CCR6, CCR8, CCR9, CCR10, CXCR2, CXCR3 and CX3CR1 compared with healthy controls. Interestingly, the frequencies of CD123hiCD303+cells were also higher in untreated patients, and reduced after treatment, and the cell surface marker CD83 was also elevated. By cell culture in vitro, pDC had defects in secreting INF$\alpha$ of IgG4-RD patients than healthy controls.

Conclusions: The excessive infiltration of $\mathrm{pDC}$ in peripheral blood and tissue but less CCR7 Defects of secreting INF- $\alpha$ of pDC in IgG4-RD may indicate less function of eliminating infection which may induce constant infection. pDC may played vital roles in the pathogenesis of IgG4-RD,

Disclosure of Interest: None declared

DOI: 10.1136/annrheumdis-2018-eular.3865

\section{AB1155 IMMUNOGLOBULIN G4 - RELATED DISEASE, A DIAGNOSTIC CHALLENGE}

P. Diéguez ${ }^{1}$, B. Gimena, A. Argibay, C. Vázquez Triñanes, M. Estévez, M. Freire, J. Fernández Martín, A. Rivera. Systemic Autoimmune diseases and Thrombosis Unit, University Hospital Complex of Vigo, Vigo, Spain

Background: The IgG4-related disease (IgG4-RD) is a chronic, inflammatory, multi-organic, systemic disease. The pathological assessment is the gold standard for the diagnosis, hallmarked by the lymphoplasmacytic tissue infiltration of mainly lgG4-plasma cells, the storiform fibrosis and the obliterative phlebitis. Objectives: The aim of this study was to analyse the features of IgG4- RD cases followed in a specific autoimmune diseases unit, since 2013.

Methods: Descriptive, retrospective study, through the review of clinical charts Medical records were reviewed for demographics information, clinical presentation, underlying conditions, laboratory and radiological data, medical and surgical treatments and clinical outcomes. All patients diagnosed by biopsy were included (international consensus pathological criteria of 2012). We excluded the possible cases of IgG4-RD when biopsy was not available or did not meet the criteria previously mentioned.

Results: Eight patients with characteristic clinical, histological and laboratory features of IgG4-RD were included. The patients were predominantly male (87.5\%), the mean age at diagnosis was $66 \pm 11$ years. ${ }^{48-80} 87.5 \%$ of the cases were consulted from other hospital Services, mainly surgical: Urology $25 \%$ (hydrocele and urinary retention), General Surgery 25\% (obstructive jaundice and forearm tumour), Vascular Surgery 25\% (abdominal aortic aneurysm), Cardiac Surgery $12.5 \%$ (thoracic aortic aneurysm) and Neurology $12.5 \%$ (hypertrophic pachymeningitis). The most commonly involved organs were vascular $87.5 \%$ (6 aorta, 1 pulmonary veins) and retroperitoneum $75 \%$, followed by renal $37.5 \%$, pancreatic $12.5 \%$, and central nervous system $12.5 \%$. It was found isolated organic involvement in only one patient (autoimmune pancreatitis). Two patients had previous malignancy: renal cells and prostate. Magnetic resonance imaging, computed tomography and FDG-PET were made in $62.5 \%$ each of them. Serum IgG4 was determined in all cases, $62.5 \%$ of patients had normal lgG4 serum levels (the upper limit of normal for serum lgG4 is $135 \mathrm{mg} / \mathrm{dl})$. Three patients $(37.5 \%)$ had elevated serum $\mathrm{lgG} 4$, the mean level was $188 \pm 38 \mathrm{mg} / \mathrm{dL}$ ((152-266). The pathological findings were dense lymphoplasmacytic infiltrate in 6 cases (75\%) with obliterative phlebitis in 5 of them, storiform-type fibrosis in 4 cases (50\%) and $\operatorname{lgG} 4 / \mathrm{lgG}$ ratio $>40 \%$ in $75 \%$ of the samples. Glucocorticoids treatment was initiated in $75 \%$ of patients, $25 \%$ were untreated for predominantly fibrotic involvement. There were treatment response in $60 \%$ of cases. $25 \%$ had a relapse after corticoid withdrawal. Only one patient received a second drug due to lack of response to Prednisone (rituximab).

Conclusions: According to the literature, IgG4-RD patients were predominantly male in their sixth and seventh decade of life. The predominant involvement in ou serie was vascular and retroperitoneal, with no cases of glandular manifestations. Highlight the high number of cases with normal serum IgG4. Most of our patients responded to corticosteroid therapy.

Disclosure of Interest: None declared

DOI: 10.1136/annrheumdis-2018-eular.7347

\section{AB1156 DRESS (DRUG REACTION WITH EOSINOPHILIA AND SYSTEMIC SYMPTOMS): LOOKS MAY BE DECEPTIVE}

R. Mistry ${ }^{1}$, A. Jain ${ }^{1}$, S. Ravi ${ }^{2}$, D. Misra ${ }^{1}$, N. Krishnani ${ }^{3}$, V. Aggarwal ${ }^{1} .{ }^{1}$ Clinical Immunology and Rheumatology, Sanjay Gandhi Post Graduate Institute, Lucknow, India, Lucknow; ${ }^{2}$ Rheumatologist, Apollo BGS Hospital, Mysuru; ${ }^{3}$ Pathology, Sanjay Gandhi Post Graduate Institute, Lucknow, India, Lucknow, India

Background: Drug reaction with eosinophilia and systemic symptoms(DRESS) is a rare, potentially life threatening multisystem disorder with fever, skin erup tions, lymphadenopathy, eosinophilia and systemic involvement most commonly after a drug exposure. These cases may mimic various rheumatological conditions. We report a series of 14 cases of DRESS who presented to Rheumatology Clinic as suspected connective tissue disease or sepsis in Northern India.

Objectives: To highlight DRESS as a common mimic of common rheumatologic conditions and sepsis and report its etiology, characteristics, treatment and prognosis

Methods: We manually searched the inpatient records of Immunology Department in SGPGI 2007-18 for the cases discharged with a diagnosis of possible/ probable/definite DRESS. The records of the patients with probable and definite DRESS according to regiSCAR critera ${ }^{1}$ were reviewed.

Results: All the 14 patients fulfilled clinical criteria for diagnosis (4 probable, 10 definite). The age of patients ranged from 9-53 years with majority in their 3 rd decade. Majority of the patients were referred to us when their counts were rising in the setting of fever and skin rashes with a suspicion of rheumatic disease/sepsis. The clinical and laboratory features of these patients are as follows (table 1): TLC: Total Leucocyte Count, AEC: Absolute Eosinophil Count, ED: Exfoliative dermatitis, F: facial oedema, M: maculopapular rash, L: Liver, K: Kidney, P: Lung G: GI, SSZ: Sulphasalazine, HRZE: Isoniazid, Rifampicin, Pyrazinamide, Ethambutol, FU: Follow up

All the patients were treated with oral steroids showing signs of clinical improvement within 4-5 days. Rashes and leucocyte count were first to respond. Transaminitis responded within a week. Mean Followup is 9.3 months. They were gradually tapered off steroids over next 3-4 months except for two patient who were lost to follow up. 
Abstract AB1156 - Table 1

\begin{tabular}{|c|c|c|c|c|c|c|c|c|c|}
\hline $\begin{array}{l}\text { Age/ } \\
\text { Sex }\end{array}$ & Drug & $\begin{array}{l}\text { Late-ncy } \\
\text { (weeks) }\end{array}$ & $\begin{array}{l}\text { Type of } \\
\text { rash }\end{array}$ & $\begin{array}{c}\text { Systemic involve- } \\
\text { ment }\end{array}$ & $\begin{array}{l}\text { TLC/AEC } \\
\text { /cu.mm }\end{array}$ & $\begin{array}{c}\text { ALT/AST } \\
I U / L\end{array}$ & Score $^{1}$ & Initial Suspected Diagnosis & $\begin{array}{l}\text { Followup } \\
\text { (months) }\end{array}$ \\
\hline $14 / \mathrm{F}$ & Phenobarbitone & 6 & $F, E D$ & $\mathrm{~L}, \mathrm{~K}$ & $23100 / 693$ & $252 / 407$ & 5 & Lupus & 4 \\
\hline $33 / F$ & Cefuroxime & 2 & $F, E D$ & $\mathrm{~L}$ & $\begin{array}{c}27600 / \\
9936\end{array}$ & $203 / 460$ & 6 & Acute viral hepatitis, sepsis or Lupus & 11 \\
\hline 9/M & $\begin{array}{c}\text { Carbamazepine or } \\
\text { HRZE }\end{array}$ & 2 & $\mathrm{M}, \mathrm{F}, \mathrm{ED}$ & $\mathrm{L}, \mathrm{K}$ & $\begin{array}{c}19800 / \\
2300\end{array}$ & $\begin{array}{l}2752 / \\
1385\end{array}$ & 7 & $\begin{array}{l}\text { ATT induced hepatitis (for TBM), } \\
\text { sepsis }\end{array}$ & 24 \\
\hline $53 / \mathrm{M}$ & Gabapentin & 7 & $F, E D$ & $L, P$ & $\begin{array}{c}21400 / \\
3424\end{array}$ & $63 / 135$ & 7 & Vasculitis, Lupus & Lost FU \\
\hline $50 / F$ & Alternative medicine & 3 & M & $L, P$ & $\begin{array}{c}39630 / \\
2830\end{array}$ & $150 / 202$ & 5 & Lupus & 24 \\
\hline $15 / \mathrm{M}$ & SSZ & 1 & ED & $L, G$ & $\begin{array}{c}28300 / \\
3100\end{array}$ & $133 / 92$ & 7 & AGE with Sepsis & 3 \\
\hline $21 / \mathrm{M}$ & HRZE & 5 & $F, E D$ & L, G, K & $\begin{array}{c}51900 / \\
3114\end{array}$ & $491 / 478$ & 8 & Lupus or Vasculitis & 8 \\
\hline $20 / F$ & SSZ & 3 & $\mathrm{~F}, \mathrm{M}, \mathrm{ED}$ & $\mathrm{L}$ & 60820/NA & $137 / 233$ & 6 & $\begin{array}{l}\text { Lupus } \\
\text { Malignancy }\end{array}$ & 3 \\
\hline $20 / F$ & Valproate & 8 & M & L, G, & $13500 / \mathrm{NA}$ & $148 / 177$ & 5 & Lupus & 24 \\
\hline $53 / \mathrm{M}$ & SSZ & 6 & $\mathrm{~F}, \mathrm{M}, \mathrm{ED}$ & $\mathrm{L}, \mathrm{K}$ & $\begin{array}{c}31300 / \\
5634\end{array}$ & $516 / 436$ & 7 & Lupus or Vasculitis & Lost FU \\
\hline $46 / \mathrm{M}$ & HRZE & 2 & M & $\mathrm{L}, \mathrm{K}$ & $24000 / N A$ & $135 / 118$ & 6 & Sepsis, ATT induced hepatitis & 1 \\
\hline $27 / F$ & SSZ & 12 & $M, E D$ & L, K & $38900 / 850$ & $94 / 96$ & 6 & Sepsis & 3 \\
\hline $32 / F$ & Leflunomide & 4 & M & $L, P$ & $10500 / 210$ & $543 / 297$ & 4 & Drug induced transaminitis & 4 \\
\hline $38 / F$ & SSZ/Leflunomide & 20 & $\mathrm{M}$, & $L, G$ & $\begin{array}{l}36400 / \\
7200\end{array}$ & $112 / 142$ & 8 & Sepsis & 3 \\
\hline
\end{tabular}

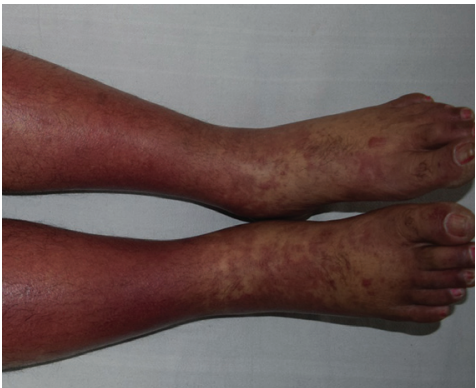

Abstract AB1156 - Figure 1

Conclusions: - Skin rash, arthritis, multi-organ failure of DRESS closely mimic rheumatologic disorders or sepsis (especially with rising TLC)

- As early diagnosis is imperative for successful outcome, low threshold of suspicion is necessary.

\section{REFERENCE:}

[1] Kardaun SH, Sidoroff A, Valeyrie-Allanore L, et al. Variability in the clinical pattern of cutaneous side-effects of drugs with systemic symptoms: Does a DRESS syndrome really exist? Br J Dermatol 2007; 156:609.

Disclosure of Interest: None declared

DOI: 10.1136/annrheumdis-2018-eular.5967

\section{AB1157 CLINICAL IMPLICATIONS OF ULTRASONOGRAPHY (US) IN MONITORING DISEASE ACTIVITY OF RELAPSING POLYCHONDRITIS (RP) AND COMPARATIVE INVESTIGATION BY US BETWEEN AURICLE OF RP, REPEATED TRAUMA AND HEALTHY SUBJECT}

S. Inotani, Y. Taniguchi, H. Nishikawa, E. Amano, S. Nakayama, Y. Terada. Department of Endocrinology, Metabolism, Nephrology and Rheumatology, Kochi Medical School, Nankoku-shi, Japan

Background: Relapsing polychondritis $(\mathrm{RP})$ is a rare systemic inflammatory disorder and might often be refractory. Therefore, the discovery of more convenient imaging modality than contrast-CT, MRI and FDG-PET/CT would be required on diagnosis and treatment.

Objectives: To assess the clinical implications of ultrasonography (US) in monitoring disease activity and diagnosis of relapsing polychondritis (RP).

Methods: Firstly, auricular chondritis of patients with RP $(n=5)$ were assessed by US before and after treatments. Second, the relationship between US findings and other serum inflammatory markers were evaluated. Moreover, the comparisons of US findings between the auricle of patients with RP $(n=5)$, repeated trauma $(n=5)$ which is similar to auricle of RP, and healthy subjects $(n=5)$ were also assessed.
Results: US finding before treatment showed low-echoic swollen auricular cartilage with increased power Doppler signals (PDS) in all cases of RP. US findings corresponded to biopsy findings. After treatment with prednisolone (PSL) combined with methotrexate, the swollen ear completely resolved. Then, US findings also showed dramatic reductions in swollen cartilage with the decrease in PDS When serum inflammatory markers completely improved, but US finding remained in 1 of 5 cases, and this case showed flare due to PSL tapering. Finally, RP could be differentiated from the damage of repeated trauma with producing subperichondrial serous effusion.

Conclusions: US of auricular cartilage in RP possibly facilitates evaluation of auricular lesions and monitoring of disease activity, especially when we consider the treatment response and the timing of drug tapering.

Disclosure of Interest: None declared

DOI: 10.1136/annrheumdis-2018-eular.1813

\section{AB1158 MALIGNANCY IN PATIENTS WITH SARCOIDOSIS: A RETROSPECTIVE COHORT STUDY FROM TURKEY}

S. Kobak ${ }^{1}$, F. Yildiz ${ }^{2}$, H. Semiz ${ }^{3}$, M. Orman ${ }^{4} .{ }^{1}$ Rheumatology, Istinye University Faculty of Medicine, LIV Hospital, Istanbul; ${ }^{2}$ Chest Diseases, Medicalpark Hospital; ${ }^{3}$ Internal Medicine; ${ }^{4}$ Statistics, Ege University Faculty of Medicine, Izmir, Turkey

Background: The relationship between sarcoidosis and malignancy is not clear yet. There is debate with different speculations in the literature in this regard, that this association may be just a coincidence and/or common pathogenetic link.

Objectives: The goal of our study was to evaluate the incidence and characteristics of malignancy in patients with sarcoidosis follow-up in a single centre.

Methods: Our study is a retrospective analysis of patients diagnosed with sarcoidosis at the single Rheumatology centre from Turkey. Electronic patient records from the years 2010 to 2016 were screened, and 131patients with the diagnosis of sarcoidosis were included in the study. Diagnosis of sarcoidosis was either a clinical diagnosis in patients with Löfgren's syndrome or confirmed by tissue biopsy in all other patients. The incidence of malignancies were evaluated in this cohort. Malignant diseases were diagnosed by histopathology. The clinical data of patients with sarcoidosis and malignant diseases were further analysed.

Results: A total of 6 patients with malignancy were identified in our cohort of 131 patients with sarcoidosis, representing an incidence of $4.6 \%$. Among them, Hodjkin lymphoma(HL) were detected in three patients, followed by one patient with breast cancer, one patient with thyroid cancer and one patient with testicular cancer. All patients had chronic sarcoidosis with pulmonary involvement, and only 1 patient(with thyroid cancer) had acute sarcoidosis with Löfgren's syndrome. HL developed concomitantly with sarcoidosis in one patient while other two patients developed disease before and after sarcoidosis diagnosis. Two patients with solid tumours (breast $\mathrm{Ca}$, testicular $\mathrm{Ca}$ ) developed malignancy years before sarcoidosis diagnosis( 1 year and 2 year espectively), while one patient developed thyroid cancer during sarcoidosis follow-up. All 6sarcoidosis-malignancy patients were survived during six year follow-up.

Conclusions: We found low incidence of malignancy in patients with sarcoidosis in our small cohort. Malignancy may develop in patients with sarcoidosis. Its may occur before, after, or concurrent with the diagnosis of sarcoidosis. The sarcoidosis-malignancy relationship can only be a coincidence and/or can be explained by 